EA 4272

\title{
Consumer Preferences for Eco, Health and Fair Trade Labels. An Application to Seafood Product in France
}

\author{
Dorothée Brécard* \\ Sterenn Lucas* \\ Nathalie Pichot ${ }^{* *}$ \\ Frédéric Salladarré ${ }^{\star * *}$
}

$2011 / 09$

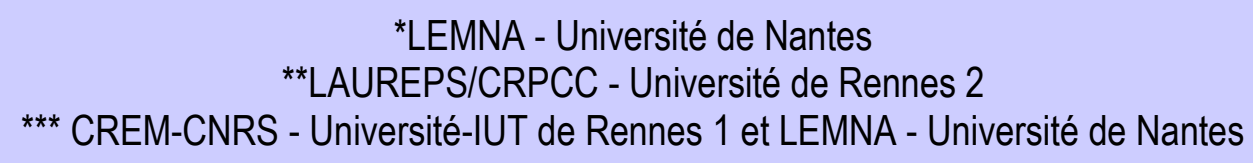

Laboratoire d'Economie et de Management Nantes-Atlantique

Université de Nantes 


\title{
Consumer Preferences for Eco, Health and Fair Trade Labels. An Application to Seafood Product in France
}

Dorothée Brécard $^{\mathrm{a}^{*}}$, Sterenn Lucas ${ }^{\mathrm{a}}$, Nathalie Pichot ${ }^{\mathrm{b}}$, Frédéric Salladarréc $^{\mathrm{c}}$

a'Université de Nantes, LEMNA, Institut d'Économie et de Management de Nantes - IAE, Chemin de la Censive du Tertre, BP 52231, 44322 Nantes Cedex 3, France.

${ }^{b}$ Université de Rennes 2, LAUREPS/CRPCC, EA 1285, place du recteur Henri Le Moal, CS 24307, 35043 Rennes Cedex, France.

'Université-IUT de Rennes 1, CREM-CNRS, LEMNA, Campus de Beaulieu, Avenue du Général Leclerc, CS 44202, 35042 Rennes Cedex, France.

\begin{abstract}
How are consumer attitudes towards eco-labeled products affected by a profusion of labels? This article provides both theoretical and empirical insight into this issue. Assuming that consumers perceive a label both as a sign of quality and of a particular characteristic of a product, we deduce theoretical determinants for preferences for three types of label: a health label, an eco-label and a fair trade label. Using a French survey on seafood products, the estimation of a rank-ordered multinomial logit with random intercepts shows a certain proximity between the profiles of pro-eco-label and pro-fair trade label consumers, whereas pro-health label individuals have a more distinct profile: The two former are more likely to be young men mainly concerned with fishing conditions, whereas the latter are older married women with children who pay attention to the product form. We relate preferences for labels to degree of altruism, environmental consciousness and other socio-economic features.
\end{abstract}

Keywords. Environmental preferences, contingent choice, eco-label, seafood.

JEL classification. C25, D11, D12, Q22.

\footnotetext{
*Corresponding author. E-mail address: dorothee.brecard@univ-nantes.fr
} 


\section{Introduction}

Promoting sustainability has been viewed as a major strategy to limit the environmental impact of consumption since the late 90's. The European Commission states on its web site ${ }^{1}$ that "sustainable consumption and production maximise business" potential to transform environmental challenges into economic opportunities and provide a better deal for consumers. The challenge is to improve the overall environmental performance of products throughout their life-cycle, to boost the demand for better products and production technologies and to help consumers in making informed choices." Indeed, the OECD (2002) underlined the importance of consumer decisions in various sectors, such as energy, food, waste and transport, since they translate into everyday actions affecting the environment.

A significant number of consumers seem to share this opinion: $21 \%$ of Europeans estimate that buying environmentally friendly products has a positive and significant impact on solving environmental problems (European Commission, 2009). Despite this, there is a "behavior gap" between consumer values and behavior (Young et al., 2010). One reason for this gap is the higher price of green products compared to standard products. Green goods are more labor-intensive; they are often produced in smaller quantity and, hence, don't benefit from large economies of scale; they involve more environmentally friendly and more expensive technologies; and their higher price can be used as a signal to consumers of their environmental friendliness (Mahenc, 2006).

Consumer behavior also depends on the amount of information they have on the environmental consequences of their consumption. The role of labels, such as organic labels, non-GMO labels and other eco-labels, is to provide such information. There is a growing literature dealing with eco-labels, including many theoretical articles analyzing the optimal policies and corporate strategies for eco-labeling in the case of both complete and incomplete consumer information when consumers are environmentally conscious. ${ }^{2}$ In the latter case, firms may be tempted to develop "greenwashing" strategies in order to benefit from the higher consumer willingness to pay for green products. Since greenwashing harms both the environment and consumer welfare, the credibility of eco-labels is a crucial issue. All theoretical articles assume a consumer demand for eco-labeled produce, that is the existence of "green consumers". Empirical papers seek to identify a green consumer profile. Older consumers are less likely to be pro-green products (Loureiro and Lotade, 2005, Srinivasan and Blomquist, 2009, Brécard et al., 2009) but they have more confidence in label information (Teisl at al., 2008). Women are generally more willing to pay a premium for a green-product (Blend and Van Ravenswaay, 1999, Loureiro, 2003, Loureiro et al., 2002, Loureiro and Lotade, 2005 Brécard et al., 2009). Some studies show that men are less influenced by label information (Teisl, et al., 2008, Bjoner et al., 2004), whereas others highlight that men are less likely to have a positive willingness-to-pay for environmental concerns, but, when they do, they are willing to pay a larger premium (Carlsson and Johansson-

\footnotetext{
${ }^{1} \mathrm{http}: / /$ ec.europa.eu/environment/eussd/escp_en.htm (accessed 28/01/2011).

${ }^{2}$ See Amacher et al. (2004), Erikson (2004), Conrad (2005), Ben Youssef and Lahmadi-Ayed (2008) and Clemenz (2010) for analyses of optimal policies in case of complete information, and Mason (2006), Ibanez and Grolleau (2008) and Mahenc (2006, 2009) for analyses in case of incomplete information. See Kuhn (2005) for a survey on eco-labeling.
} 
Stenman, 2000, Dupont, 2004). Level of education positively influences trust in ecoinformation and the willingness to choose an eco-labeled product (Teisl et al., 2008, Wessels et al., 1999). Household composition has also an impact on consumer behavior. Households with children under 18 behave in a more pro-environmental way (Loureiro et al., 2001, 2002) whereas the increased household size tends to reduce this effect (Clark et al., 2003, Kotchen and Moore, 2007).

How is consumer attitude towards eco-labeled products affected by the profusion of labels? Very few studies have attempted to understand label demand from this viewpoint. To the best of our knowledge, the only theoretical paper touching on this issue is that of Ben Youssef and Abderrazak (2009). They show that the co-existence of two eco-labels can reduce the environmental quality of a product when consumers don't know which eco-label ensures the best environmental quality of the product. They conclude that "the implication for policy is that improvement of information related to the environmental quality of products becomes a principal instrument of environmental policy in the presence of multiplicity of labels." With an empirical perspective, Loureiro et al. (2001) focus on the factors affecting consumer choice between eco-labeled organic and regular apples. They show that income and the presence of children under 18 favor organic apples, whereas age and education are not statistically significant. McCluskey and Loureiro (2003) underline that preference for organic apples over other kinds of apple is certainly due to the healthier image of organic apples: "the consumer must perceive high eating quality in order for the food product to command a premium". In a study comparing three kinds of coffee - organic, fair trade and shade grown - Loureiro and Lotade (2005) show that consumers are more willing to pay a premium for eco-labeled coffee than for organic coffee. They argue this occurs because coffee is not associated with health and consumers don't assess the health benefits associated with organic coffee consumption at the same importance as the benefits associated with other kinds of coffee. It thus seems that, in the case of several types of labels, product characteristics play a crucial role in consumer behavior. This means that Lancaster's theoretical approach (1971) is particularly appropriate for studying consumer preferences for various labels, since each label guarantees a particular quality, such as the absence of chemicals for an organic label or a low impact on the environment for an eco-label. In the first part of this paper, we adopt such an approach in order to analyze theoretical consumer preferences for three types of labels: a health label, an eco-label and a fair trade label. We assume that consumers perceive a label both as a sign of quality and of a particular characteristic of a product. Consequently, labels lead to both a vertical and a horizontal differentiation of products. This allows us to show the theoretical determinants of their ranking of labels by order of preference.

Our empirical analysis focus on fresh fish eco-labeling, which could play a key role in the conservation of the marine resources by reducing harvest rates to below natural renewable rates. According to the FAO, 75\% of fish stocks are either fully exploited, over-exploited, depleted or recovering, whereas the level of catches has remained stable since 1990, following several decades of steady growth (Washington, 2008). Fish ecolabeling could encourage fishermen and fish consumers to turn towards eco-friendly behavior. Among seafood eco-labels, the most popular one is the Marine Stewardship 
Council (MSC) ${ }^{3}$, which at present certifies fisheries catching $7 \%$ of the total global capture production for direct human consumption, and which will soon increase to 12 $\%$. This raises the question of the impact of seafood eco-labeling on consumer behavior, and a number of papers have addressed this issue. Johnston and Roheim (2006) underline that consumers are happy to change species if overfishing is sufficiently high, but that the presence of an eco-label alone is not enough to favor the choice of a lessfavored species. Women and members of environmental organizations are more likely to choose eco-labeled fish (Wessels et al., 1999, Johnston et al., 2000, Roheim, 2004, Brécard et al., 2009). The age effect is not clear-cut, according to Brécard et al. (2009) and Salladarré et al. (2010), younger people are more likely to choose eco-labeled fish, while Johnston et al. (2001) show a reverse tendency. The importance of species and purchase criteria are underlined by all studies. To the best of our knowledge, ecolabeling of seafood products has not yet been studied while taking into account the presence of other labels. In this paper, we attempt to fill this gap.

In order to carry out an empirical analysis, we undertook an econometric analysis of French consumer preferences for three hypothetical labels for fresh fish: a heath label guaranteeing that the products do not contain toxins; an eco-label ensuring that the product is caught in an environmentally friendly way; and a fair trade label guaranteeing that conditions within the production chain meet minimum standards such as decent working conditions. The analysis uses data from a French survey into seafood preferences carried out on 911 respondents in France by the RICEP ${ }^{4}$ in 2010 (Baranger et al., 2010). We relate consumers' label ranking with their socio-economic situation; their purchase criteria for fresh seafood products; and their level of information about and perceived responsibility of the impact of fishery on marine resources.

Estimating a rank-ordered multinomial logit with random intercept allowing for unobserved heterogeneity, our results show some similarity between the profiles of proeco-label and pro-fair trade label consumers, whereas pro-health label individuals have a distinct profile. The sociological profile of a health labeled fish advocates is a relatively old (over 55 years) married woman with children who pays particular attention to the product form; whereas eco-label and fair trade label advocates are more likely to be men, young, and mainly concerned about fishing conditions. Fair trade label buyers exhibit one other particularity: they are more frequently single parents than the two other groups. Finally, eco-label advocates are characterized by a higher education level. This tends to corroborate our theoretical approach assuming that the three labels are differentiated from each other by a vertical and a horizontal feature. Hence, according to their degree of altruism, consumers differ in their willingness to pay for others' well-being, although, depending on their moral and social values, each

\footnotetext{
${ }^{3}$ The MSC is currently the subject of a controversy sparked by Jacquet and Pauly's article in Nature in September 2010.

${ }^{4}$ The RICEP (Réseau d'Information et de Conseil en Economie des Pêches) is the French Network of Information and Advice in Economics of Fisheries. It coordinates the activity "Commercial Optimization" of the project PRESPO (Sustainable Development of the Artisanal fisheries in the Atlantic Area) conducted by 11 Portuguese, Spanish and French partners. This activity aims at identifying mechanisms allowing to ensure a consistent price for operators upstream and downstream of the marketing chain and to optimize the value chain of products of artisanal fisheries. Fish eco-labeling is one of the studied valorization tools.
} 
consumer has an ideal label and would like to purchase a product stamped with a label as near as possible as this ideal.

The remainder of the paper is structured as follows. In Section 2, we analyze the theoretical determinants of preferences for various labels. In Section 3, we introduce the database and the econometric method. In Section 4, we analyze our empirical results and compare them with the theoretical predictions. Section 5 brings the paper to a conclusion.

\section{Consumer preferences for differentiated labels.}

In the economic literature dealing with eco-labels, ${ }^{5}$ they are generally perceived as a sign of quality or a sign of variety. In the vertical product differentiation models, the eco-label rewards the environmental quality of a good, that is its low environmental impact compared to non-labeled product. Models extending Mussa and Rosen's framework (1978) assume that, while all consumers prefer a less polluting product, they differ in their marginal willingness-to-pay for green quality. In other words, if all products were sold at the same price, all consumers would purchase a labeled one. In addition, the demand for the eco-labeled product rises with the degree of environmental awareness of consumers (Amacher et al., 2004, Ben Youssef and Lahmandi-Ayed, 2008, Ben Youssef and Abderrazack, 2009, Ibanez and Grolleau, 2008).

In the horizontal differentiation models, based on d'Aspremont et al.'s model (1979), each consumer has an ideal variety, which does not necessarily correspond to the most environmentally friendly one. In other words, if all products were sold at the same price, some consumers would prefer an eco-labeled product while others would prefer an unlabeled one. Hence, consumers gain utility when the difference between their ideal variety and the variety they really consumes decreases. Since consumers' tastes are heterogeneous, ideal varieties are also heterogeneous. Green demand thus depends on the disutility due to this difference. What distinguishes a green variety from another is the warm glow induced by a contribution to a better environment (Eriksson, 2004, Conrad, 2005) or the partial internalization of the environmental externality (Boyer et al., 2006, Clemenz, 2010).

What is the best way to consider consumer preferences for an eco-label when it is in competition with other labels, in particular a health label and a fair trade label? The double differentiation model, following Neven and Thisse (1990), provides a wellsuited framework for this analysis. In this framework, each consumer, according to their moral and social values, has an ideal label and would like to purchase a product carrying a label as near as possible to this ideal. Furthermore, consumers view the label as a sign of the "quality" of contribution to the well being of others and they differ in their willingness to pay for this positive external effect. Accordingly, products are characterized by double differentiation: a horizontal feature, the label type, and a vertical one, an altruistic quality. Obviously, these two features are closely connected. We will first present theoretical consumer demand, before inferring the determinants of the demand for labeled products.

\footnotetext{
${ }^{5}$ We restrict our analysis to credible eco-labels, assuming that eco-labeling provides complete and reliable information to consumers.
} 


\subsection{Consumer demand}

Each product $i$ differs from others in its quality $q_{i}$ and its label $l_{i}$, with $i$ equaling $H$ for the health labeled product, $E$ for the eco-labeled product and $S$ for the social (i.e. fair trade) labeled product. Quality $q_{i}$ measures the positive external effects of the product, with $0 \leq q_{H} \leq q_{E} \leq q_{S}$. Labels $l_{i}$ are spread on linear space $[0,1]$. We assume, without loss of generality, that $l_{H}=0,0<l_{E}<1$ and $l_{S}=1$

In line with product differentiation models, we assume that each consumer buys one unit of the product or none. This assumption amounts to considering that the quantity of product to be purchased is fixed or, alternatively, that satisfaction is only gained from the consumption of the first unit of the product. Accordingly, each consumer can only choose between one of the three products or none. The consumer is characterized by a marginal willingness to pay for quality, $\theta$, and an ideal label, $\lambda$. We assume that $\theta$ is uniformly distributed over $[0,1]$ and $\lambda$ is uniformly distributed over $[0,1]$. Consumers are thus uniformly distributed on the unit square $[0,1] \times[0,1]$. We suppose that the market is fully covered.

Consumer willingness-to-pay for quality $q_{i}$ is defined by $\theta q_{i}$ and measures the gross surplus of consumer $\theta$ when choosing quality $q_{i}$ of the product. Otherwise, the distance between the ideal label, $\lambda$, and the label of the consumed product tends to reduce the consumer's gross surplus. We assume that this gross surplus decreases from $\tau\left|\lambda-l_{j}\right|$, with $\tau \geq 0$, when label $l_{j}$ is chosen instead of label $\lambda$. In addition, we consider a composite good $x$ bought by the consumer when deciding not to consume any labeled product. Consumer preferences are therefore represented by the following utility function:

$$
U_{i}(\theta, \lambda)=x+\theta q_{i}-\tau\left|l_{i}-\lambda\right|
$$

Consumers select their optimal variant by maximizing utility subject to the budget constraint $x+p_{i} \leq r$, with $r$ income, $p_{i}$ the price of product $i$ (with $p_{i} \geq p_{j}$ if $q_{i} \geq q_{j}$ ), $r$ and $p_{i}$ being measured in terms of $x$. Consequently, consumer $(\theta, \lambda)$ chooses product $i$ which maximizes his net surplus $u_{i}(\theta, \lambda)$ defined by:

$$
u_{i}(\theta, \lambda)=r+\theta q_{i}-\tau\left|l_{i}-\lambda\right|-p_{i}
$$

In order to analyze consumer preferences, we define $\hat{\theta}_{j k}(\lambda)$, consumers who are indifferent between products $j$ and $k$, as follows:

$$
\hat{\theta}_{j k}(\lambda)=\frac{p_{k}-p_{j}+\tau\left(l_{j}+l_{k}\right)-2 \tau \lambda}{q_{k}-q_{j}}
$$

Their marginal willingness-to-pay for quality decreases with $\lambda$. This means that, for these consumers, the proximity (resp. distance) to their most preferred label $l_{j}(e . g$. health) must be outweighed by a high (resp. low) willingness-to-pay for $q_{k}$ (e.g. ecological) in order for them to be indifferent between both labels. Consumer rationality entails the usual assumption of transitivity of preferences. This requires that $\hat{\theta}_{H E}(\lambda) \leq \hat{\theta}_{H S}(\lambda) \leq \hat{\theta}_{E S}(\lambda)$ for all $\lambda$ in $[0,1]$. These inequalities are fulfilled when quality $q_{E}$ is closer to quality $q_{S}$ than to quality $q_{H}\left(q_{S}-q_{E}<q_{E}-q_{H}\right)$ and the price gap 
between eco-labeled and heath labeled products $p_{E}-p_{H}$ is lower than the transport cost between both varieties $\tau l_{E}$.

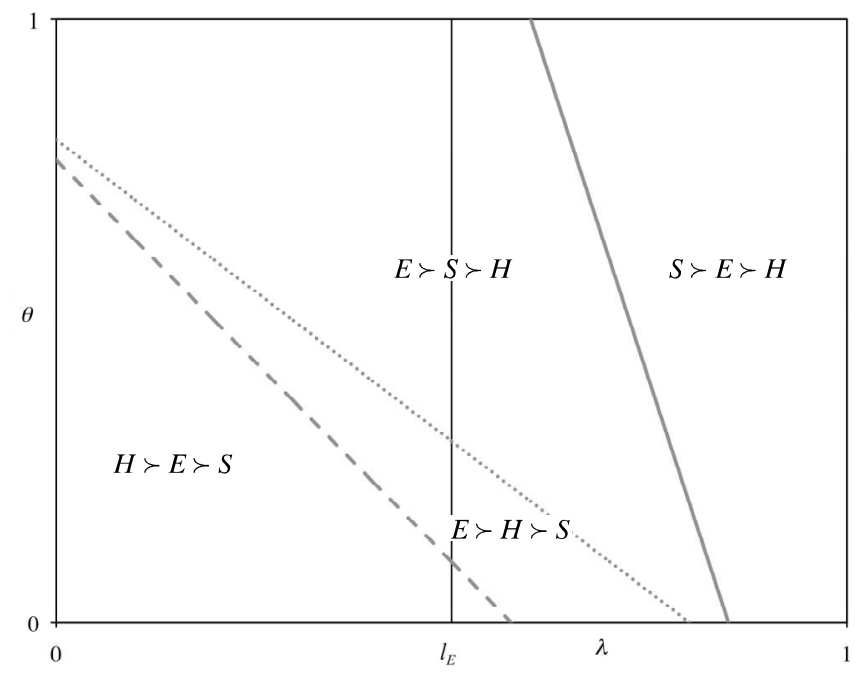

Figure 1. Consumer space (with $l_{E}=0.5$ )

$$
-\hat{\theta}_{H E}(\lambda) \ldots \hat{\theta}_{H S}(\lambda)-\hat{\theta}_{E S}(\lambda)
$$

Indifferent consumers $\hat{\theta}_{H E}(\lambda), \hat{\theta}_{E S}(\lambda)$ and $\hat{\theta}_{H S}(\lambda)$ are represented in the space $(\lambda, \theta)$ in Figure 1 above. We can characterize consumer preferences for health label, eco-label and social label according to their types $(\theta, \lambda)$. Consumers with $\theta(\lambda) \in\left[0, \hat{\theta}_{H E}\right]$ prefer the health label to the eco-label and the eco-label to the social label. We denote this preference relation $H \succ E \succ S$. Consumers with $\theta(\lambda) \in\left[\hat{\theta}_{H E}, \hat{\theta}_{H S}\right]$ favor the eco-label and rank the labels $E \succ H \succ S$. Consumers with $\theta(\lambda) \in\left[\hat{\theta}_{H S}, \hat{\theta}_{E S}\right]$ have a preference for the eco-label too, but the order is $E \succ S \succ H$. Finally, consumers with $\theta(\lambda) \in\left[\hat{\theta}_{E S}, 1\right]$ prefer the social label and order labels $S \succ E \succ H$.

Therefore, the consumer space is divided in three parts: the demand for the health labeled product is represented by the area below the line $\hat{\theta}_{H E}(\lambda)^{6}$ where consumers have a lower willingness-to-pay for quality as their ideal variant is far from the health label. The demand for the social labeled product is shown by the area above the line $\hat{\theta}_{E S}(\lambda)^{7}$ where consumers have an ideal product near the social labeled product or compensate for the distance from the social label by a high willingness-to-pay for

${ }^{6}$ Calculating demand for each product necessitates defining $\underline{\lambda}_{j k}$ and $\bar{\lambda}_{j k}$ such as $\hat{\theta}_{j k}\left(\underline{\lambda}_{j k}\right)=1$ and $\hat{\theta}_{j k}\left(\bar{\lambda}_{j k}\right)=0: \quad \underline{\lambda}_{j k}=\left[p_{k}-p_{j}+\tau\left(l_{k}+l_{j}\right)-\left(q_{k}-q_{j}\right)\right] / 2 \tau \quad$ and $\quad \bar{\lambda}_{j k}=\left[p_{k}-p_{j}+\tau\left(l_{j}+l_{k}\right)\right] / 2 \tau$. When $\underline{\lambda}_{H E}<0$ and $\bar{\lambda}_{H E} \leq 1$ (as in Figure 1), $d_{H}=\hat{\theta}_{H E}(0) \times \bar{\lambda}_{H E} / 2$. When $\underline{\lambda}_{H E}>0$ and $\bar{\lambda}_{H E} \leq 1$, then $\hat{\theta}_{H E}(\lambda)$ cuts the upper side of the square for $\lambda=\underline{\lambda}_{H E}$ and $d_{H}=\left(\bar{\lambda}_{H E}+\underline{\lambda}_{H E}\right) / 2$.

${ }^{7}$ When $\underline{\lambda}_{E S}>0$ and $\bar{\lambda}_{E S}>1, d_{S}=\left(1-\hat{\theta}_{E S}(1)\right) \times\left(1-\underline{\lambda}_{E S}\right) / 2$. When $\underline{\lambda}_{H E}>0$ and $\bar{\lambda}_{E S} \leq 1$ (as in Figure 1), $d_{H}=\left(2-\bar{\lambda}_{E S}-\underline{\lambda}_{E S}\right) / 2$. 
quality. Green demand corresponds to the area between the lines $\hat{\theta}_{H E}(\lambda)$ and $\hat{\theta}_{E S}(\lambda){ }^{8}$ Some consumers, whose ideal variety is close to the eco-label but whose willingness-topay for quality is low, will choose the health labeled product because it is cheaper. Others, whose ideal variety is close to the eco-label too but whose willingness-to-pay for quality is high will buy the social labeled product because of its better quality. Accordingly, the closer a consumer's ideal variety is to the health label, the higher their willingness-to-pay for quality must be if they are to buy the green product. Conversely, the closer a consumer's ideal variety is to the social label, the lower their willingnessto-pay for quality must be if they are to buy the green product.

Since $\hat{\theta}_{j k}(\lambda)$ is a decreasing function of $\lambda$, and increases with price difference $p_{k}-p_{j}$ and with quality gap $q_{k}-q_{j}$, the lower the price of a product and the greater its quality in comparison with its closest competitor, the higher its market share. In order to develop our demand analysis, we turn now to the determinants of the critical consumer parameters $\theta$ and $\lambda$.

\subsection{The determinants of consumer preferences}

The intensity of consumer preference for the altruistic quality is measured by $\theta$, which is influenced by a number of factors. First, $\theta$ can be interpreted as the degree of impure consumer altruism (Andreoni, 1990). Indeed, consumers are more directly concerned by their health than by environmental quality and generally very indirectly concerned by the working conditions of production. Their marginal willingness-to-pay for others, $\theta$, is thus linked to their degree of altruism, which is in inverse relation to the link between consumption and quality assured by the label (Kotchen and Moore, 2007).

Secondly, $\theta$ can be interpreted as the marginal rate of substitution between income and quality, so that a higher $\theta$ is equivalent to a lower marginal utility of income and thus a higher income (Tirole, 1988). It thus increases with income. It tends to also increase when a consumer is well-informed about the health, environmental and social issues of fishing and consumption of seafood products. Furthermore, sensitivity to the positive external effects may also rise with confidence in the certifying organization, level of education and environmental and/or social involvement (OECD, 2005). Obviously, $\theta$ is explained by the socio-economic characteristics of consumers.

The consumer's ideal label $\lambda$ depends on their relative concern about health, environmental and social equity issues. Note that health, environmental and social concerns are generally strongly related, as shown in studies dealing with eco-labeling (Grankvist and Biel, 2001, 2007, Torgler and Garcia-Valiñas, 2007), and that it is not easy to disentangle the factors explaining preference for one label over another. Nevertheless, we suppose that consumers are more likely to consume health labeled products when they are very concerned about their health and that of their families and they are worry about the health risks of seafood products, especially if their degree of altruism, $\theta$, is low. They are more likely to be eco-consumers when their environmental consciousness is greater and when they feel strongly about environmental degradation (Ek and Söderholm, 2008, Arkesteijn and Oerlemans, 2005), or when their ideal label is

${ }^{8}$ In all cases, $d_{E}=1-d_{H}-d_{S}$ 
close to the health label rather than the eco-label but their degree of altruism is high. Consumers tend to buy fair trade labeled produce when their desire for social justice is dominant over health and environmental issues, or when their ideal label is close to the eco-label rather than the fair trade label but their degree of altruism is high.

Note that consumers who are particularly concerned about their health almost never buy a fair trade labeled product and consumers mainly worried about social conditions of production will probably never purchase a health labeled product. In contrast, green consumers may select the health label when their willingness-to-pay is low or the fair trade label when their willingness-to-pay is high.

In more general terms, $\theta$ and $\lambda$ are both determined by altruism, social norms and intrinsic motivation (Frey and Stutzer, 2006), ethical values and beliefs, customs, culture and social, political and moral values (Berglund and Matti, 2006, Torgler and García-Vilañas, 2007). Furthermore, we are concerned with a credence good. In order to put a value on the characteristics promoted by the label, consumers need to be informed about any issues involved in the production and consumption of the good. Accordingly, consumer knowledge level is another crucial determinant of $\lambda$ and $\theta$.

Price and quality also have a significant effect on consumer choice. When consumers think that the product closest to their ideal is expensive and/or of low quality in comparison with the neighboring product, they are less likely to buy their ideal variant, and will instead choose the neighbor. This alternative choice will be favored by a low cost of deviation from their ideal label, as in this case there is little reluctance to change and no strong habits formed.

The above analysis highlights the main theoretical determinants of label ranking. In the following section, we use a French survey on seafood labeling in order to look at the main characteristics of respondents according to their label ranking and to draw a parallel with our previous predictions.

\section{The database and the econometric model}

\subsection{Data}

The data used for our empirical analysis come from a survey carried out during April-June 2010 in France by the RICEP (2010). The purpose of this survey was to investigate French consumer perception of and purchase intentions for labeled fresh seafood products. The survey consisted of around fifty questions dealing with the perception of the fishing industry, purchase criteria for fresh seafood products, purchase intentions for three type of labels: health, eco and fair trade, willingness-to-pay for labeled seafood, and socio-economic situation. The database includes 911 questionnaires completed in face-to-face interviews. The sample is representative of the French population. Respondents' socio-economic characteristics are given in Table A.1 in the appendix. This survey is well suited for a comparative analysis of label type demand.

Before turning to the econometric analysis, a description of the data will be given. Only $6 \%$ of respondents answered "unlabeled" to the question "if you have to buy fresh fish and that you have to choose between the following four types of products, at the same price, would you choose: unlabeled, health labeled, eco-labeled or fair trade 
labeled?" whereas $40 \%$ answered "health labeled", $31 \%$ "eco-labeled" and $23 \%$ "fair trade labeled". Without deeper analysis, this typology tends to suggest a vertical differentiation between labeled and unlabeled products and a horizontal differentiation between the three labels. Our analysis therefore focuses on answers to the following question:

"If labels were proposed for seafood products, you would prefer (check as many preferences as you wish; If more than one, prioritize them from 1 - most important, to 3 - least important): a health label (a label guaranteeing the products do not contain toxic substances), an eco-label (a label guaranteeing the products were caught in an environmentally friendly way), and a fair trade label (a label guaranteeing that production conditions meet minimum standards such as decent working conditions)". Note that the label definitions were based on a pre-survey that showed that these were the labels people had in mind. Table 1 shows that the health label is more frequently ranked first than the eco-label, itself ranked first more often than the fair trade label.

\begin{tabular}{cccc}
\hline \multicolumn{4}{c}{ Table 1. Respondents' preference ordre for labels } \\
\hline Label & Health label & Eco-label & Fair trade label \\
\hline Rank 1 & $45.0 \%$ & $32.8 \%$ & $22.2 \%$ \\
Rank 2 & $24.1 \%$ & $50.0 \%$ & $42.0 \%$ \\
Rank 3 & $30.9 \%$ & $17.2 \%$ & $35.8 \%$ \\
Index & 2.14 & 2.16 & 1.86 \\
\hline Source: RICEP (2010), data from survey PRESPO
\end{tabular}

Table 1 highlights consumer heterogeneity: $45 \%$ of individuals ranked the health label first, while 50\% ranked the eco-label second and about $36 \%$ of respondents ranked the fair trade label third. We calculated a weighted index for each label. We define $I_{i}=3 x_{i 1}+2 x_{i 2}+x_{i 3}$ with $I_{i}$ the index for the label $i$ and $x_{i k}$ the percentage of individuals selecting the label $i$ with a rank $k(k=1,2,3)$. Taking the figures from Table 1 , we see that the index is almost the same for the three labels. This result also suggests a horizontal differentiation between labels. Whereas with the raw data the health label arrives in the first place, if all choices are taken into account with an index, the result is modified and the eco-label arrives in first place followed by the health label and the fair trade label.

Using the three variables, a correlation matrix was computed for all label type rankings ${ }^{10}$. Not surprisingly, the correlation coefficients are highly negative. Nonetheless, the interesting result is that the 'distance' between the eco-label and the fair trade label is less than the distance between them and the health label. There is a significant gap between the preferences of consumers prioritizing the health label and the preferences of consumers prioritizing the eco and fair trade labels. This result is in line with our assumption that the degree of consumers' impure altruism plays a

\footnotetext{
${ }^{9}$ The number of observations is 892 . The sum by rank for each label is not equal to $100 \%$ for ranks 2 and 3: this is due to the fact that some respondents were indifferent in their second choice and chose two labels at the rank 2 (the sum by lines for the rank 2 and 3 is equal 200\%). The index is given by the mean reply, the possible scores ranging from 3 when the label is ranked first to 1 when the label is ranked third.

${ }^{10}$ The correlation between the health label and the eco-label is equal to about -0.52 , between the health label and the fair trade label to approximately -0.54 , and between the eco-label and the fair trade label to about -0.31 .
} 
significant role in their ranking of the three labels, since consumers are more directly concerned by their health than by environmental quality and production conditions.

Table 2 supports this result: the ecolabel can be seen "between" the health and the fair trade labels. More than $75 \%$ of respondents who ranked the health label in first place ranked the eco-label in second place and about $70 \%$ of respondents who ranked fair trade label in first place ranked the eco-label in second place, whereas for those who ranked the eco-label first, there is a relatively even split between the health label and the fair trade label for second place. This result may reflect consumers' environmental awareness, since the eco-label focuses on the environmental consequences of a product from cradle to grave, whereas the health label only appraises the absence of harmful content, like chemicals, and the fair trade label doesn't deal with the environmental friendless of the product. In any case, it is in line with our theoretical assumption, which places the eco-label between the health label and the fair trade label in the consumer preference space. Furthermore, these results highlight the double dimension of labels: seafood products stamped with an eco-label, a health label and a fair trade label are differentiated from each other vertically and horizontally.

\begin{tabular}{|c|c|c|c|c|}
\hline \multicolumn{5}{|c|}{ Table 2 Respondents' conditional frequencies for labels ${ }^{11}$} \\
\hline & \multirow[b]{2}{*}{ Labels } & \multicolumn{3}{|c|}{ Rank 1} \\
\hline & & Health label & Eco-label & Fair trade label \\
\hline \multirow{3}{*}{ Rank 2} & Health label & & $49.1 \%$ & $35.9 \%$ \\
\hline & Eco-label & $76.3 \%$ & & $70.7 \%$ \\
\hline & Fair trade label & $48.4 \%$ & $61.8 \%$ & \\
\hline \multirow{3}{*}{ Rank 3} & Health label & & $50.9 \%$ & $64.1 \%$ \\
\hline & Eco-label & $23.7 \%$ & & $29.3 \%$ \\
\hline & Fair trade label & $51.6 \%$ & $38.2 \%$ & \\
\hline \multicolumn{2}{|c|}{ Observations } & 401 & 293 & 198 \\
\hline
\end{tabular}

Source: RICEP (2010), data from survey PRESPO

According to the empirical studies reviewed in the introduction, the label issue should be linked to explanatory variables related to consumption criteria (price, geographical origin, wild $v s$ farmed origin, fishing technique, degree of exploitation of the products, appearance, reputation of the seafood product, vendor advice, and nutritive quality of the product) and socio-economic features (gender, age, marital status, presence of children at home, education level, professional situation, income level, and type of habitat). We outlined in section 2.2 that the choice between labels may also be related to product price, and, in addition, to consumers' degree of altruism, income, knowledge, education and relative interest in health, environmental and social equity issues. We thus expect a significant influence from the following consumer characteristics: sense of responsibility about resource degradation, perceived level of fishery regulation, expected impact of labels on the environment, beliefs about the most credible structure for establishing labels (public institute, professional structure, NGO), flexibility (impulsive choice or not when buying seafood products), perceived gustative quality of seafood products, and expected health effects of seafood products.

\footnotetext{
11 The number of observations is 892 . The sum for each rank is not equal to $100 \%$ for the ranks 2 and 3 : this is due to the fact that some indifferent respondents in their second choice have chosen two labels at the rank 2 (the sum by column is then equal to $200 \%$ ).
} 
These explanatory variables are described in Table A.1, where the index calculated using Table 1 is applied for all the variables in order to define general socio-economic characteristics according to the label chosen. These socio-economic features differ noticeably according to their favored label. The pro-health-labeling respondents are more frequently older, female, in a couple with children, not well educated. Concerning the product characteristics, they pay attention to the nutritional quality, to the product reputation, but are less worried about the wild $v s$ farmed origin of the fish and to the fishing technique. They know exactly what they want to buy when they buy seafood products. They are more confident in labels established by professional structures. In contrast, pro-eco-labeling respondents are more frequently younger, male, in a couple, well educated and earning a high income. When they consume seafood products, they pay attention to the wild $v s$ farmed origin of the fish and to the geographical origin of the fish. They are more confident in labels if they are certified by an NGO. Similarly, pro-fair trade labeling respondents are more frequently young, male, but they are single, not well-educated, farmers/self-employed, without employment or manual workers and earn a low income. When they consume seafood products, they pay attention to the price. They think that labels reduce consumers' impact on the environment. They are also more confident in labels certified by an NGO.

Finally, it is worth noting that face-to-face interviews may produce a number of biases. First, this type of data collection is prone to social desirability biases, which describe the tendency of respondents to reply in a manner that will be viewed favorably by others. Although the respondents were not invited in the present survey to rank the different criteria used in their fish purchasing behavior, the proportion of respondents that chose a given item along the ordered scale of possible answers shows that quality characteristics are at the top of their priorities whereas the environmental criterion and fishing techniques are cited by the lowest proportion of the population (see Table A.1). Surprisingly, this result contradicts the tendency of respondents to reply in a manner that will be viewed favorably by others. Overall, we consider that the social desirability biases are limited. Secondly, a potential 'laziness' in the answers to the 'agreement' questions when similar questions are presented sequentially may also induce a bias. To reduce this bias, the survey was divided into four parts, which were presented in four different orders. This means each respondent was randomly given one of four versions of the survey. Each econometric specification takes into account the order with four dummy variables (one for each version), meaning any laziness bias should be low ${ }^{12}$.

Our descriptive analysis of consumer characteristics according to their label ranking gives rise to a preliminary consumer typology. In order to test consumer preferences, in the following section we reinterpret our theoretical framework using a random utility model.

\subsection{The multinomial logit random utility model}

In our survey, the respondents rank the health label, the eco-label and the fair trade label in order of preference, which means the rank-ordered random utility model provides an appropriate framework for analyzing our data. We use a model close to

\footnotetext{
${ }^{12}$ This is due to the fact that one part of the survey may be placed at the beginning or at the middle or at the end of survey.
} 
Jonhston and Roheim's model (2006). To model unobserved heterogeneity, we allow a random component in each intercept term as a measure of variation on the intrinsic label utility across respondents ${ }^{13}$.

In our model, the assignment of each rank is treated as a sequential choice process where respondents make a discrete choice between the alternatives. The rank orderings are broken down into sequences of choices. There are two decision stages: in the first, all three labels are available, and in the second, a choice is made between the two remaining alternatives. Accordingly, a rank ordered multinomial logit can be used to model consumer rankings of all the labels in a given choice set. Using such a specification, the case of incomplete rankings, when respondents only get to the first decision stage, can easily be handled.

In order to explicitly exhibit all the determinants of preferences for labeled products, we rewrite utility function (1) in a more general form:

$$
V_{k j}=X_{k} \beta_{j}+Y_{j} \gamma_{j}+\varphi_{j}
$$

where $V_{k j}$ is the utility $u_{j}(\theta, \lambda)$ obtained by consumer $k$, with type $(\theta, \lambda)$ from consuming product $j$ stamped with label $l_{j}$, with $j$ in the label set $L=\{H, E, S\} . X_{k}$ is a row vector of consumer k's socio-economic characteristics; $Y_{j}$ is a row vector of features of the product $j ; \beta_{j}$ and $\gamma_{j}$ are vectors of parameters associated with $X_{k}$ and $Y_{j}$ respectively; and $\varphi_{j}$ is a random intercept for each type of label $\left(\varphi_{H}=0\right.$ making the health label alternative the reference category). $X_{k}$ includes the characteristics discussed above (e.g. income, information, level of education, environmental and/or social involvement, degree of altruism) and also some other characteristics, such as presence of children in the household, family size, etc.

This reformulation of the utility function allows us to give the consumer's random utility definition:

$$
U_{k j}=V_{k j}+\varepsilon_{k j}
$$

with $\varepsilon_{k j}$ the i.i.d. residual error term measuring the unobservable component.

As a consequence, the probability that consumer $k$ prefers, for instance, eco-labeled product $E$ to all the other products in the set $L$ can be defined as the probability that $U_{k E}$ is higher than both $U_{k H}$ and $U_{k S}$. More precisely, the probability that ranking $E \succ S \succ H$, such that $U_{k E}>U_{k S}>U_{k H}$, holds can be expressed as a multinomial logit (McFadden, 1974). The probability of label $E$ being in the first place can be defined by a multinomial logit for the entire set of labels $L$. The probability of label $S$ being ranked in second position can be expressed by a multinomial logit too, but only for the set of remaining labels, $S$ and $H$. In the third step, the final choice is known as the first and second preferences are known. Therefore, the product of the two multinomial logits gives the probability of the entire label ranking (Luce, 1959):

$$
\operatorname{Pr}(E \succ S \succ H)=\frac{e^{V_{k E}}}{\sum_{l \in L} e^{V_{k l}}} \times \frac{e^{V_{k S}}}{\sum_{l \in\{H, S\}} e^{V_{k l}}}
$$

\footnotetext{
${ }^{13}$ On this issue, see Train (2003).
} 
Similarly, we can express the probability of any ranking, denoted $R_{i}=\left\{l_{1}, l_{2}, l_{3}\right\}$, with $l_{r}$ the $\mathrm{r}^{\text {th }}$ ranked label, as follows:

$$
\operatorname{Pr}\left(R_{i}\right)=\frac{e^{V_{k_{1}}}}{\sum_{r=1}^{3} e^{V_{k l_{r}}}} \times \frac{e^{V_{k l_{2}}}}{\sum_{r=2}^{3} e^{V_{k l_{r}}}}
$$

Beyond the inclusion of individual specific explanatory variables, our model includes alternatives specific covariates by applying a random intercept to each type of label allowing an unobserved heterogeneity to exist between the alternatives. The random intercepts models allow us to classify respondents into a common latent class. The choice probability is also conditional on random effects in addition to the exogenous variables. Estimation of the rank-ordered multinomial logit model with unobserved heterogeneity is carried out by maximum likelihood estimation which is approximated via a Gauss-Hermite quadrature (Skrondal and Rabe-Hesketh, 2003, Rabe-Hesketh et al., 2004).

\section{Results}

The results of the multinomial logit model with random intercept are reported in Table 3. Note that the health label is the reference category. The socioeconomic factors, the seafood product characteristics and the perception of consumers will be successively analyzed.

\section{- Please insert Table 3 -}

Socioeconomic characteristics play an important role in the choice of label, confirming the results of studies on eco-labeling (Wessells et al., 1999, Johnston et al., 2000, Brécard et al., 2009, Salladarré et al., 2010, Schumacher, 2010). In comparison to pro-health label individuals, French pro-eco-label consumers are more likely to be male, relatively young, well-educated; and the pro-fair trade label consumers are more frequently male, relatively young, and less frequently married (pro-fair trade label consumers are on average less well-educated than pro-eco-label consumers). Our results are in line with the health-related attitudes of European fish consumers identified by Pienak et al. (2010), since the segment of consumers with a low interest in health is made up of a greater proportion of the young and male.

Older consumers (over 55 years) are less positive towards eco-labeling: this may be due to higher awareness of environmental issues among young people (Schumacher, 2010, Whitmarsh et al., 2006). Salladarré et al. (2010) found no gender effect for French eco-label demand, concluding there is no evidence of a higher sensitiveness of women to environmental issues ${ }^{14}$ and eco-labeling. ${ }^{15}$ In contrast our results show a gender difference. The fact that women are more prone to consume health label products may be associated with family consideration (as they are the principal carers, Lewis, 2002), whereas the interest of men may be associated with the working environment, which may explain the stronger attraction to a fair trade label. This result can be related to other studies showing that women tend to be more engaged in private (household-

14 See Arora and Cason (1999), Stern et al. (1993), Zelezny et al. (2000).

${ }^{15}$ See Brécard et al. (2009) for a discussion with European data, Wessells et al.(1999) for a discussion with US data and Johnston at al. (2000) for an international comparison. 
oriented) pro-environment behavior and men in public (society-oriented) proenvironment behavior (Hunter and Hatch, 2004). Health labels are associated with private considerations and it may be preferred to the eco-label by women, leading to a crowding out effect. The reverse effect is found for men, the crowding out effect advocates a pro-environment behavior at the expense of other concerns (Rasinski et al., 1994). The multiplicity of labels leads consumers to rank labels and to reveal their priorities. Living alone increases the preference for fair trade labels (as well as the fact of having children at home, but the effect is only significant at the $15 \%$ level). This result may be linked to a greater social awareness from people living alone. In such cases, the social insecurity is potentially higher: the poverty rate is higher, and the consequences of unemployment may be more dramatic, there being only one wageearner (Esping-Andersen, 2002).

Respondents with post-graduate qualifications are more likely to be pro-eco-label, in line both with our theoretical analysis and other empirical studies on eco-labeling (Blend and VanRavenswaay, 1999, Budak et al., 2006). The education level may impact on consumer attitudes through their knowledge of environmental issues and their treatment of eco-information. More educated individuals attach more importance to ecoinformation (Teisl et al., 2008) and knowledge is positively linked with the eco-label demand (Blomquist and Whitehead, 1998, Van Kempen et al., 2009). Moreover, since education level and income are highly correlated, highly-educated consumers are likely to be more willing to pay for environmental quality. Neither income nor education level significantly influence the choice of a pro-fair trade label. The role of the willingnessto-pay for the social quality in consumers' choice cannot therefore be validated.

Several differences were found between consumers according to their professional classification. The results are not reported in detail here due to the fact that, since the French classification takes into account the level of education, the variables education and occupation are strongly correlated (see on this point Solon, 2002, Fershtman et al., 1996). The demand for the fair trade label is higher for the following categories: farmer, self-employed and manual workers. These professions may feel empathy for other workers and hence pay special attention to working conditions. In other words, their ideal label may be close to the fair trade label. Conversely, the demand for a health label is higher for consumers without an occupation (principally retirees and housewives). One surprising result is that those in intellectual professions do not show a marked preference for an eco-label when a health label is also proposed, which runs contrary to studies on eco-labeling (Brécard et al., 2009). It may be due to the fact that education level, which is significant, is correlated with professional situation.

Previous studies have shown the importance of purchasing criteria in seafood product consumption (Wessells et al., 1999, Jaffry et al., 2004) as well as in other food consumption (Bernues et al., 2003). For this article, purchasing criteria were analyzed using several factors: the price, the geographical origin, wild vs farmed origin, the fishing technique, the degree of exploitation of the product, the appearance, the reputation of the product (its prestige), vendor advice, and the nutritive quality of the product. To test the reliability of the answers, a correlation matrix was calculated for all purchasing criteria. Apart from the price variable, all the variables are positively related: this may be due to underlying factors which could be revealed through a factor 
analysis ${ }^{16}$. Two factors appeared relevant: the first factor encompasses four variables (geographical origin, wild $v s$ farmed origin, fishing technique, degree of exploitation) and the second also encompasses four variables (appearance, reputation of the product, vendor advice, and the nutritive quality of the product). The first factor can be considered as a production process factor, whereas the second one may be thought of as a product characteristic factor.

Compared to the health label, the process factor is positively linked to a demand for eco-labeling and fair trade labeling: the more consumers pay attention to the production process, the more they are pro-eco-label or pro-fair trade label. This is in line with previous studies (Jaffry et al., 2004, Bernues et al. 2003). The product factor is negatively correlated with a demand for eco-labeling and fair trade labeling with respect to the health label. These results corroborate the idea that ecological and fair trade label consumers are more altruistic than health label consumers. The link between altruistic attitudes and more ecological behavior has been highlighted in previous studies (Clark et al., 2003, Kotchen and Moore, 2007). For pro-health label consumers, the importance of product characteristics is probably linked to the specific nature of seafood products for which visual aspect and freshness are associated with quality and health. Not surprisingly, for the pro-eco-label and fair trade label individuals, the link is with the process factor because eco-labeling is mostly concerned with environment-friendly techniques of production and fair trade labeling is mostly concerned with fair working conditions during production. For consumers, these kinds of label appear to be a means of certifying the production process.

This conclusion is reinforced by the fact that concern about the impact of consumer behavior on resources favors preferences for an eco-label and a fair trade label. However, curiously, the effect is only significant for the pro-fair trade label individuals. Similarly pro-eco-label and pro-fair trade label consumers consider that labels reduce consumer impact on the environment (this is strongest for the pro-fair trade label individuals). Therefore, consumers definitely differentiate labels according to their degree of environmental awareness and altruism and pro-eco-label and pro-fair trade label consumers are more altruistic than pro-health-label individuals. Consequently they pay more attention to the impact of their consumption on the environment, even if the state of environment has no immediate impact on them. They are also more attentive to the efficiency of environmental solutions. Furthermore, they are more likely than prohealth label respondents to believe that a label's credibility is improved if it is established by certifying organizations independent of professional bodies, in particular if it established by an NGO. The confidence in the public institutions is also higher for pro-fair trade label individuals (at the level of 15\%).

In their purchasing behavior, again compared to pro-health label respondents, profair trade label consumers do not always know exactly what they want to buy (at the

\footnotetext{
16 The Bartlett test of sphericity concludes that a factor analysis is relevant and the Kaiser-MeyerOlkin measure of sampling adequacy increases when the price variable is omitted. To pick the right number of factors, we used the Kaiser and the Cattell criteria, and Horn's parallel analysis. For each factor, Cronbach's alpha statistic, which determines the internal consistency of items in a survey instruments to determine its reliability, was computed, equal to 0.70 for the first (process) factor and 0.64 for the second (product). According to Nunnaly (1978), a score of 0.7 obtained on a substantial sample is an acceptably reliable coefficient but lower thresholds are sometimes used in the literature.
} 
$15 \%$ level). Accordingly, individuals favoring a fair trade label are less fixed in their habits than others. Grankvist and Biel (2001) and Johnston et al. (2000) suggest a similar result for eco-labeled food compared non-labeled food consumers. Finally, there is no difference in preference for the types of label based on the two following criteria: seafood products being beneficial for health and seafood products being tasty. While pro-health label consumers advocate a label guaranteeing that seafood products do not contain toxic substances, this is not necessarily linked with a belief that seafood products are good for the health.

In order to reduce the 'laziness bias', our model includes dummy variables, which take note of the random distribution of the survey to respondents. None of the dummy variables is significant, thus the order of the survey does not impact on responses. Table 3 shows the results of a random intercept model. The variance of the random effect for the social label compared to the health label is higher than the variance for the eco-label compared to the health label suggesting a greater distance between the social label and the health label than between the eco-label and the health label. The positive correlation between the random effects suggests a proximity between the eco-label and the social label.

\section{Conclusion}

When choosing agri-food, consumers face a profusion of labels, each extolling specific qualities of the food, and are often confused about the guarantees given by these labels. Consumer attitudes are therefore different if they face a single label or a multitude. Up until now, theoretical and empirical literature on labels has mainly focused on the issue of consumer choice between an eco-labeled product and a non labeled one. This article provides new insights into consumer preferences for labels in the case of multiple labels.

Our theoretical model lays down expected consumer label preference ranking when they believe that labels provide information on both the "altruistic quality" (i.e. the welfare it provides to others), and the characteristic (i.e. healthiness, environmentally friendliness and decent working conditions) of the product. Building on a double differentiation model, we show how the consumer choice between labels may be related to their degree of altruism, income, knowledge, education and relative interest for health, environmental and social equity issues.

Our empirical analysis allows us to test the determinants of consumer ranking of the three labels, using data from a French survey on seafood products carried out on 911 respondents. Our results enable us to give the sociological profiles of consumers who have a preference for health labeled, eco-labeled and fair trade labeled seafood products. They show that the profiles of pro-eco-label and pro-fair trade label consumers are quite similar, whereas pro-health label individuals clearly differ. Prohealth label individuals are slightly older, married women with children, conscious of the product form, whereas pro-eco-label and pro-fair trade label consumers are younger, male and concerned about the fishing conditions. In addition, pro-fair trade label individuals are more frequently single parents and pro-eco-label respondents have a higher education level.

These results are consistent with our theoretical approach, which assumes that the three labels are differentiated from each other by a vertical and a horizontal feature. 
Hence, consumers choose labeled produce according to their degree of altruism, which determines their willingness to pay for labels guaranteeing an increase in others' welfare through an improvement of environmental or working conditions, and they also choose the products closest to their ideal varieties, which differ according to their ethical and social values. Potential consumers of eco-labeled or fair trade labeled fish are more altruistic than consumers of health labeled fish. They are also greener since they are more aware of the environment, they feel more responsible for environmental degradation and they are more confident in labels' ability to limit the harmful impact of consumption on the environment. 


\section{Appendix}

\begin{tabular}{|c|c|c|c|c|c|c|c|}
\hline \multirow[b]{2}{*}{ Variables } & \multicolumn{3}{|c|}{ Descriptive statistics } & \multicolumn{4}{|c|}{ Index* } \\
\hline & Mean & Min & Max & & $\begin{array}{c}\text { Health } \\
\text { label }\end{array}$ & $\begin{array}{l}\text { Eco- } \\
\text { label }\end{array}$ & $\begin{array}{c}\text { Fair } \\
\text { trade } \\
\text { label }\end{array}$ \\
\hline \multicolumn{8}{|l|}{ Gender } \\
\hline Men & 0.561 & 0 & 1 & & 1.953 & 2.200 & 1.979 \\
\hline Women & 0.439 & 0 & 1 & & 2.285 & 2.123 & 1.775 \\
\hline \multicolumn{8}{|l|}{ Age } \\
\hline Less than 30 years & 0.127 & 0 & 1 & & 1.904 & 2.263 & 1.962 \\
\hline 30-39 years & 0.453 & 0 & 1 & & 2.078 & 2.210 & 1.834 \\
\hline $40-54$ years & 0.333 & 0 & 1 & & 2.158 & 2.179 & 1.860 \\
\hline More than 55 years & 0.087 & 0 & 1 & & 2.427 & 1.960 & 1.799 \\
\hline \multicolumn{8}{|l|}{ Marital status } \\
\hline Couple & 0.648 & 0 & 1 & & 2.184 & 2.177 & 1.809 \\
\hline Single & 0.352 & 0 & 1 & & 2.058 & 2.119 & 1.968 \\
\hline \multicolumn{8}{|l|}{ Children at home } \\
\hline No & 0.580 & 0 & 1 & & 2.126 & 2.132 & 1.889 \\
\hline Yes & 0.420 & 0 & 1 & & 2.159 & 2.190 & 1.831 \\
\hline \multicolumn{8}{|l|}{ Education } \\
\hline Primary & 0.093 & 0 & 1 & & 2.380 & 1.810 & 1.962 \\
\hline Secondary & 0.313 & 0 & 1 & & 2.103 & 2.167 & 1.851 \\
\hline Tertiary & 0.352 & 0 & 1 & & 2.126 & 2.170 & 1.858 \\
\hline Tertiary - post-graduate & 0.242 & 0 & 1 & & 2.121 & 2.252 & 1.855 \\
\hline \multicolumn{8}{|l|}{ Household income } \\
\hline Less than $1500 € /$ month & 0.219 & 0 & 1 & & 2.161 & 2.047 & 1.943 \\
\hline Between 1500 and $2400 € /$ month & 0.253 & 0 & 1 & & 2.135 & 2.149 & 1.883 \\
\hline Between 2400 and $3450 € /$ month & 0.315 & 0 & 1 & & 2.117 & 2.192 & 1.822 \\
\hline More than $3450 € /$ month & 0.213 & 0 & 1 & & 2.147 & 2.226 & 1.832 \\
\hline \multicolumn{8}{|l|}{ Professional situation } \\
\hline Farmer / Self-employed & 0.052 & 0 & 1 & & 1.915 & 2.234 & 1.957 \\
\hline Executive and intellectual profession & 0.137 & 0 & 1 & & 2.154 & 2.341 & 1.740 \\
\hline Employed (Intermediary profession) & 0.197 & 0 & 1 & & 2.287 & 2.149 & 1.730 \\
\hline Manual workers & 0.331 & 0 & 1 & & 1.963 & 2.209 & 1.919 \\
\hline Without employment & 0.283 & 0 & 1 & & 2.288 & 1.996 & 1.932 \\
\hline \multicolumn{8}{|l|}{ Seafood characteristics** } \\
\hline \multirow{2}{*}{ Appearance } & \multirow{2}{*}{7.838} & \multirow{2}{*}{0} & \multirow{2}{*}{10} & Low & 2.081 & 2.198 & 1.866 \\
\hline & & & & High & 2.163 & 2.141 & 1.864 \\
\hline \multirow{2}{*}{ Price } & \multirow{2}{*}{7.832} & \multirow[t]{2}{*}{0} & \multirow{2}{*}{10} & Low & 2.119 & 2.196 & 1.779 \\
\hline & & & & High & 2.148 & 2.143 & 1.895 \\
\hline \multirow{2}{*}{ Nutritional Quality } & 5.391 & 0 & 10 & Low & 1.954 & 2.173 & 1.960 \\
\hline & 5.391 & 0 & 10 & High & 2.249 & 2.147 & 1.808 \\
\hline Wild or farmed orioin & 4429 & 0 & 10 & Low & 2.148 & 2.137 & 1.866 \\
\hline Wild or farmed origin & 4.429 & 0 & 10 & High & 2.135 & 2.170 & 1.863 \\
\hline Geogranhic orioin & 3767 & 0 & 10 & Low & 2.174 & 2.150 & 1.845 \\
\hline Geographic origin & $3 . / 0 /$ & 0 & 10 & High & 2.117 & 2.162 & 1.878 \\
\hline Vendor advice & 3549 & 0 & 10 & Low & 2.006 & 2.216 & 1.893 \\
\hline & & & & High & 2.229 & 2.118 & 1.845 \\
\hline Product reputation/prestige & 3.153 & 0 & 10 & Low & 1.933 & 2.198 & 1.945 \\
\hline & 3.153 & 0 & 10 & High & 2.323 & 2.121 & 1.793 \\
\hline Resource availability & 3123 & 0 & 10 & Low & 2.101 & 2.177 & 1.850 \\
\hline Resource avallability & 3.123 & 0 & 10 & High & 2.177 & 2.138 & 1.878 \\
\hline Fishing Technique & 2.249 & 0 & 10 & Low & 2.162 & 2.164 & 1.836 \\
\hline
\end{tabular}




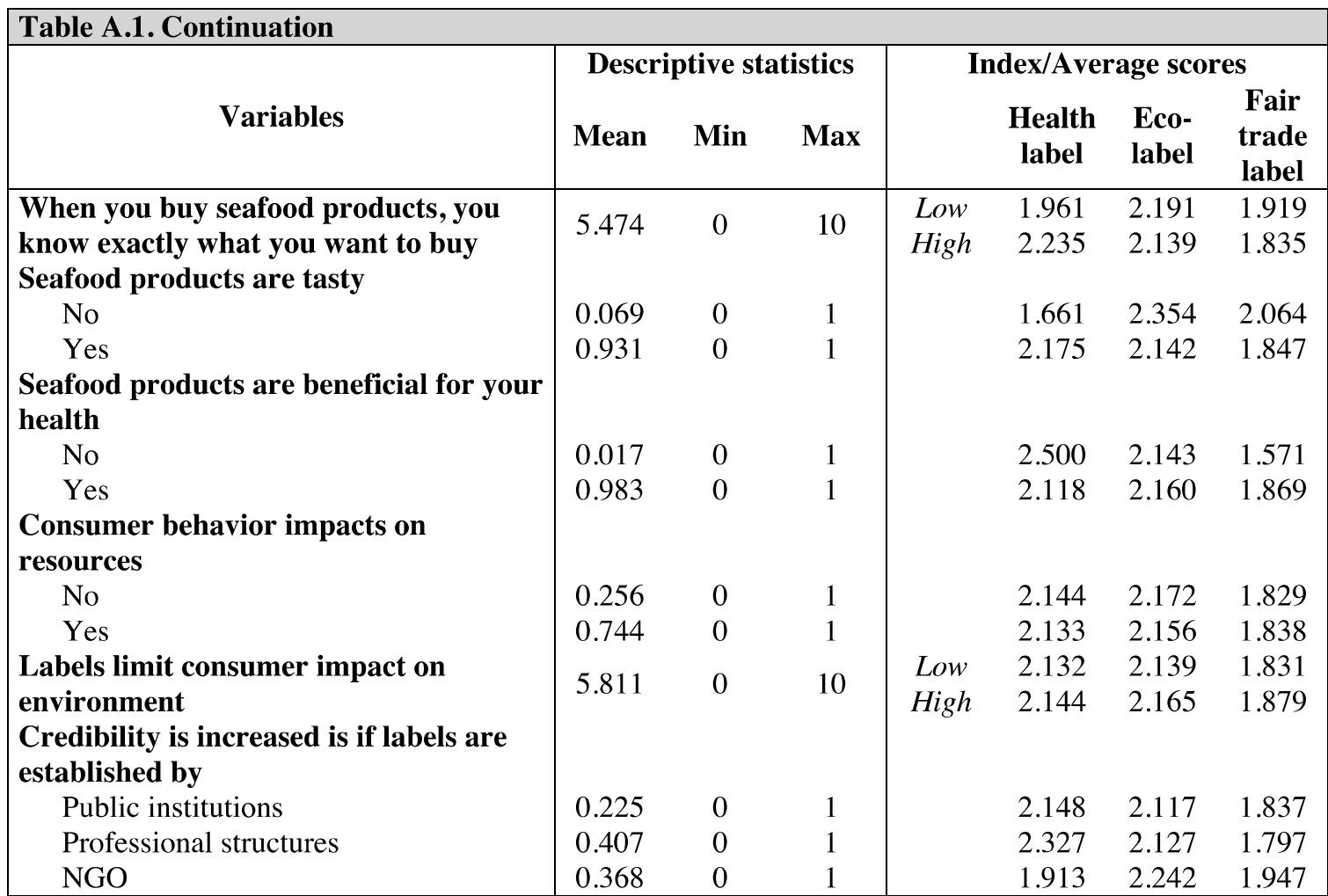

* The index is given by the mean reply, the possible scores ranging from 3 when the label is first ranked to 1 when the label is third ranked (See Table for further details).

** Two indexes for continuous variables (scored from 0 to 10) have been calculated: the 'Low' one for answers below the mean value of the concerned variable (second column of the Table) and the 'High' one for answers above the mean.

Source: RICEP (2010), data from survey PRESPO.

\section{Acknowledgements}

We are indebted to participants of the PRESPO program and to members of the RICEP for helpful materials and comments. The usual disclaimer applies.

\section{References}

Amacher G., Koskela E., Ollikainen M. (2004), Environmental quality competition and eco-labeling, Journal of Environmental Economics and Management 47, 284-306.

Andreoni, J. (1990), Impure Altruism and Donations to public-Goods - a theory of Warm-Glow Giving, Economics Journal, 100 (401), 464-477.

Arkesteijn K., Oerlemans L. (2005), The early adoption of green power by Dutch households: An empirical exploration of factors influencing the early adoption of green electricity for domestic purposes, Energy Policy, 33, 183-196.

Arora S., Cason T.N. (1999). Do community characteristics influence environmental outcomes? Evidence from the toxics release inventory. Southern Economic Journal, 65(4), 691-716.

D'Aspremont, C., Gabszewicz, J. and Thisse, J. F. (1979). On Hotelling's Stability in Competition, Econometrica, 47, 1145-1151. 
Baranger L., Lesage C.M., Ollivier P., Salladarré F., Brécard D., Lucas S., Pichot N., (2010), Quel potentiel commercial pour des produits de la pêche écolabellisés ? Attentes et comportement des consommateurs, AGLIA, 41p.

Ben Youssef A., Abderrazak C. (2009), Multiplicity of Eco-Labels, Competition and the environment, Journal of Agricultural \& Food Industrial Organization 7, special issue: Quality Promotion through Eco-labeling.

Ben Youssef A., Lahmandi-Ayed R. (2008), Eco-labelling, Competition and Environment: Endogenization of Labelling Criteria, Environmental and Resource Economics, 41, 133-154.

Berglund C. and Matti S. (2006), Citizen and consumer: the dual role of individuals in environmental policy, Environmental Politics, 15 (4), 550-571.

Bernues A., Olaizola A., Corcoran K. (2003), Labelling information demanded by european consumers and relationships with purchasing motives, quality and safety meat, Meat Science, 65 (3), 1095-1106.

Bjorner T. B. Hansen L. G., Russell C. S. (2004), Environmental labeling and consumers' choice - an empirical analysis of the effect of the Nordic Swan, Journal of Environmental Economics and Management, 47, 411-434.

Blend, J. R. and Van Ravenswaay, E. O. (1999), Measuring Consumer Demand For Ecolabeled Apples. American Journal of Agricultural Economics, 81 (5), 1072-1077

Blomquist G.C. and Whithead J.C. (1998). Resource quality information and validity of willingness to pay in contingent valuation, Resource and Energy Economics, 20, 179-196

Boyer M., Mahenc P., Moreaux M. (2006), Environmental Protection, Consumers Awareness, Product Characteristics and Market Power, in Boyer, M., Hiriart, Y. and D. Martimort (editors), Frontiers in the Economics of Environmental Regulation and Liability, 121-152.

Brécard, D., Hlaimi B., Lucas S., Salladarré F., Perraudeau Y. (2009), Determinants of demand for green products: An application to eco-label demand for fish in Europe, Ecological Economics, 69, 115-125.

Budak F., Budak D.B., Kacira O.O. and Yavuz M.C. (2006), Consumer willingness to pay for oraganic sea bass in Turkey, The Israeli Journal of Aquaculture - Bamighed, 58(2), 116-123.

Carlsson F., Johansson-Stenman O. (2000), Willingness to pay for improved air quality in Sweden, Applied Economics, 32, 661-669.

Clark C. F., Kotchen M. J., Moore M. R. (2003), Internal and external influence on proenvironmental behavior: Participation in a green electricity program, Journal of Environmental Psychology, 23, 237-246.

Clemenz G. (2010), Eco-Labeling and Horizontal Product Differentiation, Environmental and Resource Economics 45, 481-497.

Conrad K. (2005), Price Competition and Product Differentiation when Consumers Care for the Environment", Environmental and Resource Economics, 31, 1-19.

Dupont D.P. (2004), Do children matter? An examination of gender differences in environmental valuation, Ecological Economics, 49, 273-286.

Ek K., Söderholm P. (2008), Norms and economics motivation in the Swedish green electricity market, Ecological Economics, 68(1-2), 169-182. 
Eriksson C. (2004), Can green consumerism replace environmental regulation? A differentiated product example, Resource and Energy Economics, 26, 281-293.

Esping-Andersen G. (2002), Why We need a New Welfare State, Oxford, Oxford University Press

European Commission (2009), Europeans' attitudes towards the issue of sustainable consumption and production, Flash Eurobarometer, 256.

Fershtman, C., K. M. Murphy and Y. Weiss (1996), Social Status, Education and Growth, Journal of Political Economy, 104, 108-132.

Frey, B. S. and Stutzer, A. (2006), Environmental Morale and Motivation, in Alan Lewis (Editors), The Cambridge Handbook of Psychology and Economic Behavior, Cambridge, UK, Cambridge University Press.

Grankvist, G., Biel, A. (2001). The importance of beliefs, purchase criteria and habits for the choice of environmentally friendly food products, Journal of Environmental Psychology, 21, 405- 410.

Grankvist, G., Biel, A. (2007). Predictor of purchase of eco-labeled food products: a panel study, Food Quality and Preference 18(4), 701-708

Hunter L. M., Hatch A., Johnson A., 2004, Cross National Gender Variation in Environmental behaviors, Social Science Quarterly, 85(3), 677-694.

Ibanez L., Grolleau G. (2008), Can Ecolabeling Schemes Preserve the Environment?, Environmental and Resource Economics, 40(2), 233-249.

Jacquest J., Pauly D. (2010), Seafood stewardship in crisis, Nature, 467, 28-29.

Jaffry, S., Pickering, H., Ghulam, Y., Whitmarsh D. and Wattage, P. (2004), Consumer choices for quality and sustainability labeled seafood products in the UK, Food Policy, 29, 215-28.

Johnston R. J., Roheim C. A. (2006), A battle of taste and environmental Convictions for Ecolabeled Seafood: a contingent Ranking Experiment, Journal of Agricultural and Resource Economics, 31(2), 283-300.

Johnston R. J., Wessells C. A., Donath H. and Asche F. (2001) Measuring Consumer Preferences for Ecolabeled Seafood: An International Comparison, Journal of Agricultural and Resource Economics 26(1), 20-39.

Kotchen, M. J. and Moore, M. R. (2007), Private provision of environmental public goods: Household participation in green-electricity programs, Journal of Environmental Economics and Management, 53, 1-16.

Kuhn, M. (2005) The Greening of Markets: Product Competition, Pollution and Policy Making in a Duopoly, Edward Elgar.

Lewis J. (2002), Gender and Welfare State Change, European Societies, 4(4), 331-357.

Loureiro M. L. (2003). Rethinking new wines: implications of local and environmentally friendly labels, Food Policy, 28(5-6), 547-560.

Loureiro M. L., Lotade J. (2005). Do fair trade and eco-labels in coffee wake up the consumer conscience?, Ecological Economics, 53(1), 129-138.

Loureiro M. L., McCluskey J. J. and Mittelhammer R. C. (2002), Will Consumers Pay a Premium for Eco-labeled Apples?, The Journal of Consumer Affairs, 36(2), 440-453.

Loureiro, M. L, McCluskey, J. J., Mittelhammer, R. C. (2001), Assessing Consumer Preferences For Organic, Eco-Labeled, And Regular Apples, Journal of Agricultural and Resource Economics, 26(02), 404-416. 
Luce, R.D. (1959). Individual choice behavior. New York, NY: Wiley.

Mahenc, P. (2008), Signaling the environmental performance of polluting products to green consumers, International Journal of Industrial Organization, 26, 59-68.

Mahenc, P. (2009), Wasteful labeling, Journal of Agricultural \& Food Industrial Organization 7(2), article 6.

Mason, C. F. (2006), An Economic Model of Eco-Labeling, Environmental Modelling and Assessment, 11,131-143.

McCluskey J. J., Loureiro M. L (2003) Consumer Preferences and Willingness to Pay for Food Labeling: A Discussion of Empirical Studies, Journal of Food Distribution Research, 34(3), 95-102.

McFadden D. (1974), Conditional Logit Analysis of Qualitative Choice Behavior, in P. Zarembka (ed.), Frontiers of Econometrics, New York, NY, Academic Press.

Mussa, M., Rosen, S. (1978), Monopoly and Product Quality, Journal of Economic Theory, 18, 301-317.

Neven D., Thisse J. F. (1990), On Quality and Variety Competition, in J.J. Gabszewicz, J.-F. Richard and L. Wolsey, eds., Economic Decision Making: Games, Econometrics and Optimization. Contributions in Honour of J. Drèze. Amsterdam, North-Holland, 175-199.

Nunnally, J. C. (1978), Psychometric theory, New York: McGraw-Hill.

OCDE (2002b), Towards Sustainable Household Consumption? Trends and Policies in OECD Countries. Paris.

Pienak Z., Verbeke W., Olsen S.O., Hansen K.B. and Brunsø K. (2010). Health-related attitudes as a basios for segmenting European fish consumers. Food Policy 35, 448455.

Rabe-Hesketh, S., Pickles A. and Skrondal A. (2004), GLLAMM Manual, U.C. Berkeley Division of Biostatistics, Working Paper Series 160.

Rasinski K. A., Smith T. W., Zuckerbraun S. (1994). Fairness Motivations and Tradeoffs Underlying Public Support for Government Environmental Spending in Nine Nations, Journal of Social Issues, 50(3), 179-197.

Salladarré, F., Guillotreau, P., Perraudeau Y, Montfort M.-C. (2010). The demand dor seafood eco-labels in France, Journal of Agricultural \& Food Industrial Organization, 8(1), article 10.

Schumacher I. (2010), Ecolabeling, consumers' preferences and taxation, Ecological Economics 69, 2202-2212.

Skrondal A. and Rabe-Hesketh S. (2003), Multilevel logistic regression for polytomous data and rankings, Psychometrika, 68, 267-287.

Solon, G. (2002), Cross-Country Differences in Intergenerational Earnings Mobility." Journal of Economic Perspectives 16(2002): 59-66.

Srinivasan A., Blomquist G. (2009), Ecolabeled Paper Towels: Consumer Valuation and Expenditure Analysis, Journal of Environmental Management, 90, 314-320.

Stern, P., Dietz, T., Kalof, L., 1993. Values orientations, gender, and environmental concern. Environment and Behavior 25 (3), 322-348.

Teisl, M. F., Rubin, J. and Noblet, C. L. (2008), Non-dirty-dancing? Interactions between eco-labels and consumers, Journal of Economic Psychology, 29, 140-159.

Tirole, J., 1988. The Theory of Industrial Organisation. MIT Press, Cambridge, 479 p. 
Torgler, B. and Garcia-Valinãs, M. A. (2007), The determinants of individuals Attitudes Towards Preventing Environmental Damage, Ecological Economics, 63, 536-552.

Train K. (2003), Discrete Choice Models using Simulation. Cambridge University Press, Cambridge, UK.

Van Kempen L., Muradian R., Sandóval, Castañeda J.-P. (2009), Too poor to be green consumers? A field experiment on revealed preferences for firewood in rural Guatemala, Ecological Economics, 68, 2160-2167.

Washington, S. (2008), Ecolabels and Marine Capture Fisheries: Current Practice and Emerging Issues, Globefish Research Program, 91.

Wessels, C.R., Johnston, R.J. and Donath, H. (1999), Assessing consumer preferences for eco-labeled seafood: the influence of species, certifier, and household attributes. American Journal of Agricultural Economics, 81 (5), 1084-89.

Whitmarsh, D. and Wattage, P. (2006), Public attitude towards the environmental impact of salmon aquaculture in Scotland. European Environment, 16, 108-121.

Young W., Hwang K., McDonald S., Oates C. J. (2010), Sustainable consumption: green consumer behaviour when purchasing products, Sustainable Development Journal, 18(1), 20-31.

Zelezny L.C., Chua P.-P., Aldrich C. (2000), Elaborating on gender differences in environmentalism, Journal of Social Issues, 56, 443-457. 


\begin{tabular}{|c|c|c|c|c|}
\hline \multicolumn{5}{|c|}{\begin{tabular}{|c|c|c|} 
Table 3 . Estimation results of the rank ordered logit model \\
\end{tabular}} \\
\hline & \multicolumn{2}{|c|}{ Ecolabel } & \multicolumn{2}{|c|}{ Fair trade label } \\
\hline & Coefficient & SE & Coefficient & SE \\
\hline Constant & 0.434 & $(1.34)$ & -0.047 & $(1.38)$ \\
\hline \multicolumn{5}{|l|}{ Gender } \\
\hline Men & Ref. & & Ref. & \\
\hline Women & $-0.488 * *$ & $(0.24)$ & $-0.746 * * *$ & $(0.25)$ \\
\hline \multicolumn{5}{|l|}{ Age } \\
\hline Less than 30 years & Ref. & & Ref. & \\
\hline $30-39$ years & -0.392 & $(0.37)$ & -0.109 & $(0.39)$ \\
\hline 40-54 years & -0.295 & $(0.37)$ & -0.281 & $(0.39)$ \\
\hline More than 55 years & $-0.995 * * *$ & $(0.41)$ & $-0.720 *$ & $(0.42)$ \\
\hline \multicolumn{5}{|l|}{ Marital status } \\
\hline Single & Ref. & & Ref. & \\
\hline Married & 0.085 & $(0.27)$ & $-0.500^{*}$ & $(0.28)$ \\
\hline \multicolumn{5}{|l|}{ Children at home } \\
\hline No & Ref. & & Ref. & \\
\hline Yes & 0.285 & $(0.29)$ & 0.438 & $(0.31)$ \\
\hline \multicolumn{5}{|l|}{ Education } \\
\hline Secondary & Ref. & & Ref. & \\
\hline Tertiary & 0.037 & $(0.27)$ & -0.020 & $(0.28)$ \\
\hline Tertiary - post-graduate & $0.586^{*}$ & $(0.34)$ & 0.126 & $(0.35)$ \\
\hline \multicolumn{5}{|l|}{ Seafood characteristics } \\
\hline Product & $-0.456 * * *$ & $(0.09)$ & $-0.605 * * *$ & $(0.09)$ \\
\hline Process & $0.169 * *$ & $(0.08)$ & $0.165^{*}$ & $(0.08)$ \\
\hline Price & 0.073 & $(0.06)$ & $0.110^{*}$ & $(0.06)$ \\
\hline $\begin{array}{l}\text { When you buy seafood products, you know exactly } \\
\text { what you want to buy }\end{array}$ & -0.050 & $(0.04)$ & -0.064 & $(0.04)$ \\
\hline \multicolumn{5}{|l|}{ Seafood products are tasty } \\
\hline No & Ref. & & Ref. & \\
\hline Yes & -0.113 & $(0.20)$ & -0.168 & $(0.21)$ \\
\hline \multicolumn{5}{|l|}{ Seafood products are beneficial for your health } \\
\hline No & Ref. & & Ref. & \\
\hline Yes & 0.135 & $(0.23)$ & 0.304 & $(0.24)$ \\
\hline \multicolumn{5}{|l|}{ Consumer behavior impacts on resources } \\
\hline No & Ref. & & Ref. & \\
\hline Yes & 0.333 & $(0.32)$ & $0.538^{*}$ & $(0.32)$ \\
\hline Labels limit consumer impact on environment & $0.108 * *$ & $(0.05)$ & $0.123 * *$ & $(0.05)$ \\
\hline \multicolumn{5}{|l|}{ Credibility increased is if labels are established by } \\
\hline Professional structure & Ref. & & Ref. & \\
\hline Public institutions & 0.294 & $(0.30)$ & 0.465 & $(0.32)$ \\
\hline NGO & $0.777 * * *$ & $(0.28)$ & $0.692 * *$ & $(0.29)$ \\
\hline \multicolumn{5}{|l|}{ Order of survey } \\
\hline Order 1 & Ref. & & Ref. & \\
\hline Order 2 & -0.109 & $(0.32)$ & 0.2011 & $(0.34)$ \\
\hline Order 3 & -0.0026 & $(0.32)$ & -0.045 & $(0.33)$ \\
\hline Order 4 & 0.058 & $(0.06)$ & 0.400 & $(0.34)$ \\
\hline \multicolumn{5}{|l|}{ Random effects } \\
\hline Variance & 1.643 & $(0.40)$ & 1.917 & $(0.31)$ \\
\hline Covariance & \multicolumn{4}{|c|}{$1.68(0.32)$} \\
\hline $\begin{array}{l}\text { Number of observations at the individual level } \\
\text { Log Likelihood }\end{array}$ & & & .04 & \\
\hline
\end{tabular}

The reported coefficients are estimated with a multinomial logit with random effects. The significance thresholds are respectively $1 \%(* * *), 5 \%(* *)$ and $10 \%(*)$. Standard errors are in parentheses. 